\title{
ANALISIS PROFIL SOSIAL EKONOMI PEDAGANG SAYUR LESEHAN DI PASAR TRADISIONAL \\ (Studi Kasus : Pasar Tradisional Kemiri Kecamatan Medan Kota, Kota Medan)
}

\author{
KIKI CENDIKIA SINAGA ${ }^{1)}$, ZULKARNAIN LUBIS ${ }^{2)}$, \\ FAOEZA HAFIZ SARAGIH ${ }^{3)}$
}

1),2)Program Studi Agribisnis Fakultas Pertanian Universitas Medan Area

3)Program Studi Agribisnis Fakultas Pertanian Universitas Samudra Email : $\underline{\text { saragihhafiz@gmail.com }}$

\begin{abstract}
Market was an important things in economic especially traditional market, which many vegetable street vendors sell in this market everyday. Every single of them have to pay many cost meanwhile the vegetable which they sell was cheap. The aim of this research to know the profile of the vegetable street vendors in the traditional market of Kemiri, Medan Kota District, Medan City. This research used structured interview methods and in-depth interviews. The number of samples of vegetable street vendors was 10 sample. The results showed that trade income was enough for daily expenses, the education of vegetable street vendors children was fulfilled, all vegetable traders had decent house and all vegetable traders had good health. However, there's something have to noticed they don't have of legal certainty in trading, the widespread practiced of illegal levies, there's absences of training and assistance from the government in trading, and social interaction with neighbors who have never been carried out.
\end{abstract}

Keywords : Vegetable, Street Vendor, Traditional Markets, Social, Economic.

\section{PENDAHULUAN}

Menurut Undang-Undang Dasar bahwa Indonesia mengacu dalam ekonomi kerakyatan di mana di atur dalam pasal 33 Ayat 4 "Perekonomian nasional diselenggarakan berdasar atas demokrasi ekonomi dengan prinsip kebersamaan, efisiensi berkeadilan, berkelanjutan, berwawasan lingkungan, kemandirian, serta dengan menjaga keseimbangan kemajuan dan kesatuan ekonomi nasional". Sesuai dengan visi UUD 1945 pasal 27 yang berbunyi "tiap tiap warga negara berhak atas pekerjaan dan penghidupan yang layak bagi kemanusiaan". Tujuan dari undang-undang diatas adalah untuk mewujudkan sistem ekonomi kerakyatan melalui pemberdayaan perekonomian rakyat, dengan cara meningkatkan ekonomi rakyat. (Lubis, 2008).

Masyarakat dalam melaksanakan perekonomiannya di salah satu wadah yang paling banyak adalah pasar. Pasar merupakan tempat terjadinya transaksi jual beli, berdasarkan teori ekonomi pasar di bedakan menjadi dua jenis, yaitu pasar modern dan pasar tradisional. Pasar tradisional dapat juga diartikan sebagai kerumunan pedagang dan pembeli yang memperjualkan barang/jasa dimana pelaku utamanya adalah pedagang kecil, yang sebagian besar menjual komoditas pertanian (sayuran, buahbuahan beras dan lain-lain), kerajinan rakyat (tikar, topi), dan lain-lain (ayam, telur, daging). Sedangkan pembelinya adalah masyarakat 
sekitar pasar yang saling mengenal, baik dengan sesama pembeli maupun penjual (Duwit, B.S., Kumurumur, V.A. dan Moniaga, 2015)

Di dalam pasar tradisional tidak jarang ditemui para Pedagang Kaki Lima (PKL) dimana permasalahan PKL ini menjadi pekerjaan rumah bagi pemerintah kota (pemkot) yang menimbulkan dilema. Dalam mengatur tata kotanya pemerintah daerah menginginkan kota harus bersih, indah, dan nyaman. Namun di sisi lain, PKL butuh hidup dan menghidupi keluarganya, oleh karenanya mereka tidak mau pergi dari kota yang padat konsumen (Handoyo, 2012). Berdasarkan hasil prasurvey salah satu kekurangan di pasar tradisional adalah sampah banyak berserakan dan bertumpukan sehingga sering menimbulkan bau yang tidak sedap, akibatnya jika turun hujan akan becek dan kotor, tetapi saat ini kebersihan mulai ditingkatkan seperti yang dilakukan di kota Medan Sumatera Utara, dimana saat ini terdapat pasar tradisional yang penataan yang lebih baik, rapi, dan bersih sehingga nyaman untuk dikunjungi. Adapun perubahan harga jual yang fluktuatif terhadap waktu sangat berdekatan yaitu harga jual pagi dan siang berbeda. Pada sore hari harga sayur mengalami penurunan di sebabkan perubahan bentuknya dengan hal tersebut membuat pedagang sayur lesehan rentan mengalami kerugian. Berdasarkan pasal 27 UUD 1945 menyebutkan tiap warga negara berhak atas pekerjaannya dan kelayakan hidup maka dengan pasal tersebut menjadi dasar untuk melakukan penelitian profil pedagang sayur, secara mendalam untuk mengetahui kesejahteraan hidup dalam kehidupan pedagang sayur lesehan di pasar tradisional. kesejahteraan para pedagang harus di perhatikan dalam segala aspek kehidupan terutama kenyamanan serta keamanan saat berdagang di pasar. Oleh karena itu penelitian ini dilakukan untuk mengetahui kondisi social ekonomi pedagang sayur di pasar tradisional melalui profil para pedagang sayur lesehan. Kondisi social ekonomi yang di teliti adalah modal yang di peroleh, pendapatan, pelatihan usaha, bantuan pemerintah, kondisi keluarga, pendidikan anak, usaha lain, tempat tinggal, interaksi sosial, kesehatan, situasi berdagang.

\section{METODE PENELITIAN}

Penentuan lokasi penelitian dilakuan secara purposive sampling yaitu di Pasar Tradisional Kemiri Kecamatan Medan Kota yang merupakan salah satu pasar yang ada di Kota Medan dimana kepemilikan lahan pasar ini dimiliki oleh Pemerintah Kota dan masyarakat sekitar pasar. Populasi dalam penelitian adalah pedagang sayur lesehan dengan 10 orang pedagang sayur lesehan yang dipilih secara sengaja dan dianggap mewakili para pedagang sayur lainnya. pengumpulan data primer dalam penelitian ini adalah wawancara terstruktur dan in-depth interview.

Intansi yang dimaksud antara lain Badan Pusat Statistik (BPS), Perusahaan Daerah Pasar, Kantor kecamatan Medan Kota, dan Media Massa. Untuk menganalisis data yang diperoleh dari hasil penelitian dianalisis dengan menggunakan metode deskriptif kualitatif. Analisis profil pedagang sayur lesehan mengacu pada indikator yaitu modal yang di peroleh, pendapatan berdagang, interaksi sosial, bantuan pemerintah, pelatihan usaha, kondisi keluarga, pendidikan anak, usaha lain, tempat tinggal, kesehatan, situasi berdagang. 


\section{HASIL DAN PEMBAHASAN}

Pasar Kemiri di Kota Medan merupakan salah satu pasar yang telah berdiri sejak tahun 1990 yang dikelola oleh Pemerintah Kota. Seiring berjalannya waktu jumlah pedagang semakin banyak dan luas pasar pun semakin bertambah. Namun pemerintah kota tidak turut memperluas pasar yang dikelola, sehingga para masyarakat sekitar memanfaatkan lahan rumahnya untuk disewakan. Adapula lahan yang dikelola oleh Organisasi Kepemudaan (OKP) yang juga turut menyewakan lahan yang kepemilikan lahan tersebut tidak ketahui pemilik sahnya. Adapun beberapa indikator yang dikaji dalam penelitian ini yaitu sebagai berikut: 1). Modal

Pada penelitian ini, modal awal yang di peroleh para pedagang sayur di pasar tradisional kemiri kecamatan Medan Kota di ketahui di dapat dari uang pribadi dan pemberian dari mertua. Dapat dilihat dari perolehan modal awal kebanyakan para pedagang sayur lesehan mendapatkan dari uang sendiri. Hal ini dikatakan baik, pada awal berdagang sebaiknya menggunakan modal sendiri, dengan alasan bahwa keuntungan yang di peroleh dari hasil berdagang sayur dapat dimanfaatkan kembali untuk berjualan keesokan hari. Tanpa harus membagi penghasilan yang didapat untuk pengembalian modal pinjaman jika modal awal di peroleh dari pinjaman.

Pedagang sayur lesehan yang membutuhkan biaya modal harian hanya tujuh puluh ribu rupiah sampai lima juta rupiah. Akan tetapi kebanyakan para pedagang mengeluarkan modal harian sebesar satu juta rupiah sampai dua juta rupiah setiap harinya untuk berdagang sayur di pasar. Dengan penerimaan dalam berdagang kebanyakan dalam satu hari mencapai satu juta seratus ribu rupiah hingga dua juta dua ratus ribu rupiah. Dalam penelitiannya Wahyono ( 2017) menyampaikan bahwa modal berpengaruh terhadap pendapatan para pedagang karena semakin besar modal semakin besar pula pendapatan yang di dapat.

Terdapat satu pedagang yang mengeluarkan modal paling sedikit dikarenakan memiliki kebun sayur sendiri untuk kemudian dijual ke pasar. Biaya yang di keluarkan hanya untuk belanja dagangan sayur jika tidak memenuhi jumlah sayur yang akan dijual, dan membeli sayur nya juga dengan pemiliki kebun di sekitar rumahnya maka pedagang ini mendapatkan harga yang jauh lebih murah. Adapun pedagang sayur lesehan yang mengeluarkan biaya yang begitu besar karena jumlah dagangan yang di jual sangat banyak di setiap jenis sayurnya dan pedagang ini menjual jenis kentang dengan mengeluarkan modal yang lebih karena harga kentang cukup tinggi di banding harga sayuran pada umumnya sehingga membuat pedagang ini mengeluarkan biaya yang besar pula.

Untuk biaya sewa tempat berdagang para pedagang memiliki biaya yang berbeda - beda. Ada pedagang yang mengeluarkan lima belas ribu rupiah sampai tiga puluh ribu rupiah per hari. Ada juga pedagang yang mengeluarkan seratus ribu rupiah sampai delapan ratus ribu rupiah per bulan, juga biaya sewa yang di keluarkan sebesar lima juta rupiah per tahun yang diberikan kepemilik lokasi yaitu pemuda setempat. dimiliki bukan hanya satu orang tetapi banyak orang hal ini di sebabkan para pemilik tempat. Dalam hal biaya sewa tempat seluruh para pedagang mengeluarkan biaya yang berbeda-beda dan ada juga yang tidak mengeluarkan biaya tempat sama sekali. Untuk perbedaan biaya sewa tempat yang terjadi sebenarnya tidak menjadi masalah jika perbedaan harga tidak terlalu jauh. Akan tetapi dalam hal ini perbedaan harga tampak begitu jelas dan selisih 
jauh, kondisi ini sangat tidak di sarankan apalagi pemilik tempat para pedagang kebanyakan dimiliki oleh pemuda setempat dengan demikian maka penetuan harga sewa tempat dibuat sesuai ketetapan antara pemilik tempat dan pedagang.

Untuk biaya kebersihan dan keamanan para pedagang kebanyakan mengeluarkan dua ribu rupiah sampai empat ribu rupiah per harinya yang di bayarkan kepada pemuda setempat dan jumlah tersebut telah di patokkan mereka. Situasi tersebut terjadi karena wilayah tempat pedagang sayur berdagang diluar wilayah PD pasar. Sayur yang diperoleh pedagang sayur berasal dari pasar lauci, tembung, deli tua, kebun sendiri, Brastagi dan sekitar pasar. Sayuran yang di jual pedagang adalah : daun ubi, kangkung, bayam, kacang panjang, selada, sawi putih, ketimun, kentang, wortel, buncis, kol, bunga kol dan lainnya. Diantara jenis sayuran tersebut hanya sayur kol yang bertahan paling lama berkisar dua hingga tiga hari, dan jenis sayuran yang tidak tahan lama dalam satu hari adalah kangkung, bayam, kacang panjang yang mudah layu. Pedagang sayur lesehan mengambil keuntungan lima ratus rupiah sampai dua ribu rupiah dari setiap sayur yang di jual.

2). Pendapatan Berdagang

Dalam satu hari mayoritas para pedagang sayur lesehan bisa mendapatkan keuntungan bersih sebesar seratus ribu rupiah sampai lima ratus ribu rupiah pendapatan ini bisa di dapatkan pada musim - musim tertentu. Pada musim ramai seperti hari libur nasional para pembeli ramai datang ke pasar, pada perayaan hari besar agama para pembeli ramai karena untuk persiapan menyambut perayaan agama dengan cara membeli aneka bahan pokok serta pangan untuk menyambut para tamu yang akan datang kerumah mereka. Pada saaat panen petani berlimpah mereka bisa mendapatkan keuntungan jauh lebih besar karena harga modal yang di kelurkan murah serta harga yang mereka jual bisa tinggi tergantung jenis sayuran yang di jual. Dengan musim-musim tersebut para pedagang bisa mendapatkan keuntungan bersih sebesar lima ratus ribu rupiah per harinya.

Dapat dilihat pedagang sayur memiliki musim sunyi dan musim ramai pembeli. Musim sunyi dirasakan pada saat hari - hari kerja dan musim ramai terjadi pada hari libur nasional dan hari besar keagamaan. Para pedagang dalam hal ini menguasai situasi pasar berdasarkan pengalaman selama berjualan sehingga dapat menentukan jumlah volume barang dagangan yang akan dijual. Pengalaman para pedagang merupakan faktor penting dalam kegiatan berdagang dimana sesuai dengan penelitian Rosetyadi \& dan Fitrie Ariantie, (2013) yang menyatakan lama usaha/pengalaman memiliki pengaruh besar terhadap pendapatan pedagang. Untuk itu pada saat musim libur dan hari besar keagamaan jumlah dan jenis sayur agar lebih banyak agar mendapatkan keuntungan yang besar dan pada musim sunyi pembeli sebaiknya pedagang menjual jenis sayur yang paling diminati pembeli agar terhindar dari kerugian.

3). Bantuan Pemerintah

Bantuan pemerintah untuk membantu para pedagang tidak pernah diterima oleh para pedagang sayur selama berdagang di pasar tradisional. Adapun pedagang sayur menerima kredit pemerintah untuk membantu berdagang melalui pinjaman kepada bank BRI dengan bunga kecil sebesar dua persen, sedangkan kebanyakan pedagang tidak menerima kredit untuk proses berdagangnya. Untuk bantuan pemerintah di luar untuk berdagang di peroleh pedagang sayur berupa biaya pendidikan sekolah dan bantuan kebutuhan pangan seperti beras, minyak 
makan, gula. Kebanyakan para pedagang tidak mendapatkan dan mendengar kabar adanya bantuan dari pemerintah.

4). Pelatihan Usaha

Dalam hal bantuan pemerintah mayoritas pedagang tidak menerima bantuan pemerintah adapun yang menerima hanya satu kali dan itupun sudah sangat lama. Untuk pelatihan usaha seluruh pedagang sayur tidak pernah mendapatkan pelatihan usaha. Kedua hal ini sangat diperlukan oleh pedagang karena dapat menambah pendapatan dan wawasan yang lebih dalam berdagang agar lebih baik kedepanya.

5). Kondisi Keluarga

Kondisi keluarga para pedagang sayur lesehan seluruhnya baik dan lengkap seperti anak dan istri, Seluruh pedagang sayur di pasar tradisional kemiri merasa bahwa pendapatan mereka dalam berdagang memenuhi kebutuhan hidup mereka meskipun hanya pas - pasan. Dalam memenuhi kebutuhan keluarga suami mereka juga bekerja seperti : pemulung, kuli bangunan, montir, rental mobil, dan sewa papan bunga. Sedangkan pedagang lainnya suami dan istri mereka tidak bekerja karena telah meninggal dunia, dan pengangguran. Untuk suami para pedagang yang bekerja memiliki penghasilan sebesar seratus ribu rupiah hingga empat ratus ribu rupiah per hari nya. Bekerja sebagai pemulung, kuli bangunan, dan montir sebesar seratus ribu rupiah per harinya.

6). Pendidikan Anak

Pendidikan anak para pedagang sayur berbeda - beda, untuk anak para pedagang sayur tamatan SMA semua bersekolah di dalam kota Medan. Namun kebanyakan pedagang sayur yang memberikan pendidikan anak sampai bangku kuliah. Dapat dilihat para pedagang sayur lesehan sangat memerhatikan dan memprioritaskan pendidikan anak karena pendidikan anak bagi mereka sangat berharga. Hal ini sangat baik dilakukan di buktikan dengan kebanyakan anak para pedagang sayur lesehan seluruhnya berpendidikan sampai sekolah menengah atas bahkan ada juga yang sampai perguruan tinggi baik dalam maupun luar kota.

7). Usaha Lain

Para pedagang sayur lesehan memiliki usaha lainnya untuk memenuhi kebutuhan keluarga mereka. Adapun pedagang yang memiliki usaha lainnya yaitu berupa rental mobil, sewa papan bunga, montir, kuli bangunan, dan montir. Untuk usaha rental mobil dan usaha sewa papan bunga memperoleh pendapatan dua ratus ribu rupiah hingga empat ratus ribu rupiah per harinya, Belum tentu dalam satu hari ada yang memakai jasa mereka. Penghasilan rata - rata lima ratus ribu rupiah per bulan nya. Sedangkan pedagang sayur lesehan lainnya tidak memiliki usaha lainnya untuk membantu biaya kebutuhan kehidupan mereka.

Usaha lain sangat baik dilakukan dan direkomendasikan kepada pedagang sayur lainnya seperti membuka usaha jual beli online dengan dagangan yang sama atau berbeda, karena pada saat ini usaha jual beli online memiliki banyak keuntungan diantaranya adalah tidak mengeluarkan modal yang besar, para konsumen dari berbagai kalangan dan berbagai daerah, serta tidak memerlukan waktu yang banyak.

8). Tempat Tinggal

Untuk pedagang sayur lesehan kebanyakan memiliki rumah sendiri. Ada juga pedagang sayur yang masih memiliki rumah dengan cara menyewa. Para pedagang sayur lesehan kebanyakan memiliki rumah sendiri dan sebagian 
menyewa. Dengan jumlah sewa ada yang empat juta rupiah sampai enam juta rupiah per tahun. Pemilihan tempat tinggal seharusnya sesuai keinginan serta memerhatikan segi keamanan dan kenyamanan. di rekomendasikan bagi para pedagang sayur lesehan yang masih menyewa rumah dapat memiliki rumah pribadi karena dengan menyewa rumah dapat menambah pengeluaran biaya berupa harus membayar sewa rumah.

9). Interaksi Sosial

Pedagang sayur lesehan dalam melakukan interaksi sosial dengan cara menitipkan dagangannya kepada para pedagang lainnya. Dalam hal intertaksi dengan tetangga sekitar rumah seluruh para pedagang sayur lesehan tidak memiliki waktu. Interaksi sosial yang dilakukan oleh pedagang sayur lesehan dengan cara meluangkan waktu pada malam hari dan meninggalkan sementara dagangannya. Hal ini sangat baik dilakukan karena para pedagang sadar akan pentingnya kegiatan sosial diluar lingkungan tempat tinggal berupa pesta, kemalangan dan acara lainnya. Akan tetapi sangat disayangkan seluruh pedagang sayur lesehan tidak memiliki waktu untuk berinteraksi kepada tetangga sekitar, dengan alasan tidak ada waktu luang untuk berinteraksi di sebabkan waktu yang ada di manfaatkan untuk istirahat. Kegiatan ini sangat tidak baik dilakukan karena tetangga adalah orang yang paling dekat dengan kita, sebaiknya para pedagang sayur lesehan meluangkan waktu berkomunikasi dengan tetangga meskipun hanya sebentar demi terbangunnya tali silahturahmi yang baik.

10). Kesehatan

Dalam hal kondisi kesehatan para pedagang sayur lesehan seluruh sampel pedagang sayur memiliki kesehatan yang baik, serta kesehatan suami dan istri mereka juga baik dan kesehatan anak mereka juga baik. Kesehatan seluruh pedagang sayur memiliki kesehatan yang baik dapt dilihat dari fisik para pedagang sayur lesehan yang terlihat sehat dan bugar. Kondisi kesehatan pedagang sayur seperti ini harus dipertahankan agar tidak mengganggu kegiatan berdagang ataupun kegiatan lainnya. Untuk itu sebaiknya pedagang sayur harus rutin memeriksa kesehatan serta dapat meluangkan waktu untuk beristirahat demi terjaganya stamina pedagang sayur lesehan dalam melakukan aktivitas sehari hari.

11). Situasi Berdagang

Kategori tempat jualan para pedagang adalah lesehan yang berada di emperan jalan. Untuk keamanan dan kenyamanan berdagang keseluruhan pedagang merasa aman dalam berdagang dikarenakan tidak ada yang menggangu mereka dalam berdagang. Intervensi dari pihak lain untuk melakukan hal tertentu dalam berdagang kebanyakan tidak ada.

Dalam penelitian yang di lakukan kepada para responden pedagang sayur lesehan dilihat indikator kesejahteraan berdasarkan Badan Pusat Statistik (BPS) dengan beberapa indikator seperti : kependudukan, kesehatan, pendidikan, ketenagakerjaan, konsumsi dan pengeluaran rumah tangga, perumahan dan lingkungan, serta kemiskinan.

a. Kependudukan

Seluruh pedagang sayur lesehan adalah penduduk asli Indonesia yang lahir di dan besar di Indonesia dan rata - rata berumur diatas tujuh belas tahun. Maka dari itu para pedagang sayur lesehan telah memenuhi indikator. 
b. Kesehatan

Kesehatan seluruh pedagang sayur lesehan dalam keadaan sehat dan baik dilihat dari kondisi fisik para pedagang sayur saat melakukan penelitian serta pernyataan pedagang sayur lesehan yang mengatakan dalam satu tahun belakangan tidak mengalami sakit yang mengharuskan di rawat di rumah sakit. c. Pendidikan

Pendidikan pedagang sayur lesehan kebanyakan tamatan SMA dan para anak pedagang sayur lesehan seluruhnya menempuh pendidikan bahkan beberapa anak yang melanjutkan keperguruan tinggi. Pedagang sayur lesehan juga mengutamakan pendidikan anak mereka.

d. Ketenagakerjaan

Seluruh pedagang sayur lesehan memiliki usia diatas lima belas tahun dan telah memiliki pekerjaan dan dapat memenuhi kebutuhan sendiri mapun keluarga.

e. Konsumsi dan Pengeluaran Rumah Tangga

konsumsi dan pengeluaran rumah tangga untuk memenuhi kebutuhan pribadi dan keluarga pedagang sayur lesehan seperti sandang dan pangan seluruhnya terpenuhi.

f. Perumahan dan Lingkungan

Pedagang sayur lesehan memiliki rumah yang mencukupi meskipun tidak mewah dengan tipe rumah 54 serta kategori rumah permanen. Tempat tinggal pedagang sayur lesehan memiliki keamanan dan kenyamanan yang baik.

g. Kemiskinan

Seluruh pedagang sayur lesehan jika dilihat dari data badan pusat statistik tentang penduduk miskin Sumatera Utara september 2017 untuk daerah perkotaan garis kemiskinan sebesar empat ratus tiga puluh delapan ribu delapan ratus sembilan puluh empat rupiah. Sedangkan pendapatan para pedagang sayur lesehan jika di total dalam sebulan melebihi garis kemiskinan.

Dalam segala aspek kebanyakan para pedagang sayur lesehan sejahtera. Mereka memiliki alasan masing - masing ada yang beralasan karena berdagang adalah hobi dari kecil, ada yang menjawab karena untuk memenuhi kebutuhan meskipun pas - pasan dari pada menganggur dan tidak bekerja, sedangkan ada juga pedagang sayur lesehan beralasan karena memiliki ladang sayur, jadi untuk menjual hasil dari panennya pedagang ini memutuskan untuk berdagang agar hasil panennya dapat menambah kebutuhan kehidupan.

\section{KESIMPULAN DAN SARAN}

Berdasarkan hasil penelitian dapat dilihat secara umum kondisi pedagang sayur lesehan di pasar tradisional Kemiri sebagai berikut : modal yang mereka gunakan dalam berdagang diperoleh dari modal pribadi, pendapatan berdagang mencukupi dalam kehidupan sehari - hari, pendidikan anak para pedagang sayur terpenuhi, pedagang sayur lesehan seluruhnya memiliki rumah layak huni, seluruh pedagang sayur lesehan memiliki kesehatan yang baik. Namun adapun hal yang harus diperhatikan dari para pedagang sayur lesehan di pasar tradisional Kemiri yaitu : tidak adanya kepastian hukum dalam berdagang, masih adanya praktek pungutan liar yang dirasakan para pedagang sayur lesehan di pasar tradisional Kemiri, tidak adanya informasi dan bantuan pemerintah dalam mendukung kemajuan dalam berdagang, tidak adanya pelatihan yang di terima oleh para 
pedagang sayur lesehan, interaksi sosial dengan tetangga yang tidak pernah dilakukan.

\section{DAFTAR PUSTAKA}

Budi Wahyono. 2017. Analisis Faktor-Faktor Yang Mempengaruhi Pendapatan Pedagang Di Pasar Bantul Kabupaten Bantul. Jurnal. Yogyakarta

BPS Medan Kota. 2017. Kecamatan Medan Kota Dalam Angka. Medan

BPS Sumatera Utara. 2017. Sumatera Utara Dalam Angka 2017. Medan. Sumatera Utara.

Dertanto. 2007. Fluktuasi Harga, Transmisi Harga dan Marjin Pemasaran Sayuran dan Buah. Jurnal. Analisis Kebijakan Pertanian.

Dharmayati Pri Handayani, dkk. 2014. Analisis Profil dan Perkembangan Aktivitas. Jurnal. Universitas Widyagana Malang. Malang

Hatta Moh. 1963 . Persoalan Ekonomi Sosialis Indonesia . Djambatan

Indah Yuliasari. 2016. Profil Pedagang Kaki Lima Dan Evaluasi Kebijakan Publik Dalam Penataan Pedagang Kaki Lima. Jurnal . Universitas Indraprasta PGRI. Jakarta

Lubis Zulkarnain. 2008 . Koperasi Untuk Ekonomi Rakyat. Citapustaka Media Perintis. Bandung

Lulud N Wicaksono, dkk. 2014. Persepsi Pedagang Pasar Terhadap Program Perlindungan Pasar Tradisional Oleh Pemerintah Kota Semarang (Studi Kasus Pedagang Pasar Peterongan Semarang Selatan). Jurnal. Universitas Diponorogo. Semarang

Mubyarto. 2014. Ekonomi Pancasila Lintasan Pemikiran. Yogyakarta : Aditya Media

Putu Rian Kusuma Jaya, dkk . 2014. Analisis Pendapatan Pedagang (Studi Pada Pasar Anyar Di Kelurahan Banjar Tengah). Jurnal. fakultas Ekonomi Bisnis. Universitas Pendidikan Ganesha. Singaraja

Putu Rian Kusuma Jaya, dkk . 2014. Analisis Pendapatan Pedagang(Studi Pada Pasar Anyar Di Kelurahan Banjar Tengah). Jurnal. fakultas Ekonomi Bisnis. Universitas Pendidikan Ganesha. Singaraja.

Susiani Desi. 2009. Profil Sektor Informal Studi Pedagang Kaki Lima di Jalan Hang Tuah. Jurnal. Kota Tanjung pinang. 